\title{
Substituição do milho e farelo de algodão pelo milheto no concentrado da dieta de novilhos em confinamento
}

\author{
Antonio Fernando Bergamaschine ${ }^{1}$, Rosana Vieira Leão Freitas ${ }^{2}$, Walter Veriano Valério \\ Filho $^{3}$, João Francisco Pereira Bastos ${ }^{1}$, Susana Queiroz Santos Mello ${ }^{2}$, Zeneide Ribeiro \\ Campos $^{1}$
}

\footnotetext{
1 Departamento de Biologia e Zootecnia, FE-UNESP, Ilha Solteira, SP, 15385-000.

2 Programa de Pós-Graduação em Zootecnia, FE-UNESP, Ilha Solteira, SP, 15385-000.

${ }^{3}$ Departamento de Matemática, FE- UNESP, Ilha Solteira, SP, 15385-000.
}

RESUMO - Objetivou-se identificar possíveis efeitos da substituição do milho e do farelo de algodão por milheto na digestibilidade dos nutrientes da dieta e no desempenho de bovinos em confinamento. As dietas, com relação volumoso:concentrado 65:35, foram compostas de silagens de milho e milheto como volumoso (50:50, com base na matéria natural) e cinco níveis de milheto em substituição ao milho e ao farelo de algodão (0; 23; 49; 80 e 96\% da matéria natural) no concentrado. O delineamento de blocos ao acaso foi adotado em ambos os experimentos. Utilizaram-se cinco repetições no estudo de desempenho e quatro na avaliação do consumo e da digestibilidade in vivo. O consumo de matéria seca (MS) expresso em porcentagem do peso vivo (PV) e g/kgPV ${ }^{0,75}$, diminuiu linearmente com a introdução de milheto na dieta, registrando-se $2,91 \%$ e $108,5 \mathrm{~g}$ e, $2,5 \%$ e $92,53 \mathrm{~g}$ para dietas exclusivas de milho e milheto, respectivamente. As digestibilidades de MS, proteína bruta e carboidratos totais não foram afetadas, enquanto a digestibilidade do extrato etéreo diminuiu e a de fibra aumentou linearmente sem afetar os teores de nutrientes digestíveis totais. O ganho de peso vivo diário, o consumo de MS e a conversão alimentar também não foram afetados pela adição de milheto, portanto, é possível substituir o milho e o farelo de algodão por milheto em rações para bovinos em confinamento.

Palavras-chave: consumo, conversão alimentar, digestibilidade, ganho de peso

\section{Replacement of corn and cottonseed meal by pearl millet in concentrate of diets for steers in feedlot}

\begin{abstract}
The objective of the present study was to identify possible effects of replacing corn and cottonseed meal by pearl millet on digestibility of nutrients in diets and on performance of cattle in feedlots. Diets with a 65:35 roughage:concentrate ratios were composed of corn and pearl millet silages as roughage (50:50, based on natural matter) and five levels of pearl millet replacing corn and cottonseed meal $(0 ; 23 ; 49 ; 80$ and 96\% natural matter) in the concentrate. It was used random block designs in both experiments. Five replicates were used to evaluate performance and four replicates for evaluating intake and in vivo digestibility. Dry matter (DM) intake, expressed in body weight (BW) percentage and $\mathrm{g} / \mathrm{kg} \mathrm{BW}^{0.75}$ linearly decreased when pearl millet was introduced into the diet, thus $2.91 \%$ and $108.5 \mathrm{~g}$ and, $2.5 \%$ and $92.53 \mathrm{~g}$ were registered for diet exclusively with corn and pearl millet, respectively. Digestibility of dry matter, crude protein, and total carbohydrates were not affected, whereas digestibility of ether extract reduced and fiber digestibility linearly increased without affecting contents of total digestible nutrients. Daily body weight gain, dry matter intake and feed conversion were not affected by adition of pearl millet, either, therefore, it is possible to replace corn and cottonseed meal by pearl millet in rations for cattle in feedlot.
\end{abstract}

Key Words: digestibility, feed conversion, intake, weight gain

\section{Introdução}

A cultura do milheto, antes restrita às regiões Sul e Nordeste, expandiu também para a região Centro-Oeste onde inicialmente foi utilizada como cobertura vegetal, no chamado plantio direto. Além dessa tecnologia o milheto possibilita a rotação entre produção de grãos e produção animal, constituindo uma das formas de integração agricultura/pecuária. Neste tipo de manejo, o milheto, normalmente é semeado após a colheita da cultura de verão, principalmente da soja, sendo denominada cultura da safrinha. O milheto, assim implantado, pode ser usado para 
pastejo durante o outono e posterior dessecação da rebrota para viabilizar o plantio direto, ou ser conduzido para produção de grãos, em substituição ao milho, que é uma cultura mais exigente, portanto de maior risco para a safrinha. Outra possibilidade é a utilização do milheto na forma de silagem.

Christensen et al. (1984), citados por Kumar (1999), acompanharam diversos estudos sobre o potencial do milheto em dietas de novilhas em confinamento, no estado do Kansas, Estados Unidos. Os autores observaram que o milheto proporcionou ganho de peso semelhante ao obtido com sorgo $(1,32 \times 1,26 \mathrm{~kg} / \mathrm{dia})$, enfatizando que o milheto é excelente fonte de proteínas, pois, apresentou melhor equilíbrio de aminoácidos essenciais com valor biológico da proteína 10\% maior que o sorgo. No Brasil, Gonçalves et al. (2010) trabalhando com garrotes nelores substituíram 0\%, $50 \%$ e $100 \%$ do milho por milheto, e não detectaram diferenças no consumo e digestibilidade dos nutrientes, com exceção do EE, cuja digestibilidade aumentou. Observou-se escassez de informações sobre o uso do milheto na alimentação de ruminantes.

Este trabalho foi realizado com o objetivo de identificar possíveis efeitos da substituição do milho e farelo de algodão pelo milheto, em dietas de bovinos, na digestibilidade dos nutrientes bem como no ganho de peso vivo, consumo de matéria seca e conversão alimentar.

\section{Material e Métodos}

O trabalho foi realizado na Fazenda de Ensino Pesquisa e Extensão da Faculdade de Engenharia-UNESP, em Ilha Solteira, São Paulo, no período de julho a outubro de 2001. Para determinação do valor nutritivo de dietas contendo milheto em substituição ao milho e farelo de algodão, foram realizados dois experimentos. As dietas, em ambos os experimentos, foram constituídas de silagem de milho e de milheto ( $50 \%$ base natural), milho moído, milheto moído, farelo de algodão, uréia e mistura mineral (Tabelas 1,2 e 3).

O experimento para avaliar o consumo e a digestibilidade teve duração de 30 dias; sendo 20 de adaptação às instalações e às dietas e medição do consumo, três de adaptação às gaiolas de digestibilidade e sete dias de coleta de fezes. Foram utilizados 20 bezerros mestiços de origem leiteira, sem raça definida com 180-200 kg e 9-13 meses, alimentados duas vezes ao dia (8 e $16 \mathrm{~h}$ ), em quantidades que permitiam sobras de aproximadamente $10 \%$ do oferecido para medição de consumo. No período de coleta a oferta de alimentos foi controlada de maneira que as sobras fossem mínimas. As fezes foram coletadas duas vezes ao dia, antes das refeições. Após pesagem e homogeneização, alíquotas de $5 \%$ das fezes de cada animal foram embaladas em sacos plásticos e congeladas a $-10^{\circ} \mathrm{C}$. Eventuais sobras eram pesadas e amostradas, por animal e também congeladas. No final do período de coleta, as amostras de fezes e sobras foram compostas por animal, obtendo-se uma amostra média. As silagens, ingredientes e rações concentradas foram amostradas três vezes por semana.

As fezes, os alimentos e as sobras foram analisadas quanto à matéria seca (MS), matéria orgânica (MO) proteína bruta (PB), extrato etéreo (EE), matéria mineral (MM), fibra em detergente neutro (FDN) e fibra em detergente ácido (FDA), conforme metodologias contidas em Silva (1981). Os carboidratos totais (CHOT) e os valores dos nutrientes digestíveis totais (NDT) foram estimados segundo Sniffen et al. (1992). A concentração dos carboidratos não-fibrosos foi estimada através da fórmula: $\mathrm{CNF}=100-(\% \mathrm{FDN}+\% \mathrm{~PB}+$ $\%$ EE + \% Cinzas), apresentada no NRC (2001), sem considerar a proteína bruta da uréia, no tratamento que a continha. A concentração de energia metabolizável (EM) foi calculada a partirda energia digestível(ED).EM=0,82ED;ED=(NDT:100) $\times 18,45$; conforme o sistema AFRC (1993).

No experimento de desempenho, foram utilizados 25 novilhos castrados da raça Guzerá com peso vivo entre 370 a $400 \mathrm{~kg}$ e idade variando de 24 a 30 meses. Os animais foram mantidos em baias individuais, concretadas, com cochos individuais cobertos e bebedouros comuns a cada duas baias. Foram utilizadas as mesmas dietas do ensaio de digestibilidade. A alimentação era fornecida duas vezes ao dia (7 e 15 h) registrando-se a quantidade de sobras cinco vezes por semana (dias úteis). Os animais foram pesados no início do experimento e a cada 28 dias. O experimento teve duração de 100 dias, sendo 16 dias de adaptação às condições experimentais e 84 dias de coleta de dados. Foram avaliados consumo de matéria seca, ganho de peso e conversão alimentar. Silagens e concentrados foram amostrados duas vezes por semana.

As dietas foram ajustadas pelo sistema AFRC (1993), considerando as ingestões de matéria seca de 2,7 e 2,3\% do peso vivo para os animais dos ensaios de digestibilidade e desempenho, respectivamente. A relação volumoso: concentrado foi de 65:35 e o ganho de peso vivo médio diário esperado foi de 1,1 kg/dia.

O delineamento em blocos casualisados foi adotado em ambos os experimentos distribuindo-se os animais às dietas conforme seus pesos. No estudo de digestibilidade foram usados quatro bezerros por dieta, no de desempenho foram utilizados cinco novilhos por dieta. Os dados de cada parâmetro foram submetidos à análise de variância e de regressão, em função dos níveis de milheto, utilizando-se o procedimento GLM do SAS (1990). 
Tabela 1 - Composição bromatológica dos ingredientes (\% MS)

\begin{tabular}{|c|c|c|c|c|c|}
\hline \multirow[t]{2}{*}{ Ingrediente } & \multicolumn{2}{|c|}{ Silagem } & \multicolumn{2}{|c|}{ Grão moído } & \multirow[t]{2}{*}{ Farelo de algodão } \\
\hline & Milho & Milheto & Milho & Milheto & \\
\hline Matéria seca (\%) & 33,67 & 25,65 & 90,87 & 92,05 & 91,82 \\
\hline Proteína bruta & 9,62 & 9,71 & 9,50 & 14,80 & 50,00 \\
\hline Extrato etéreo & 2,32 & 2,77 & 6,15 & 5,54 & 3,36 \\
\hline Matéria mineral & 6,88 & 12,74 & 1,97 & 2,80 & 6,66 \\
\hline Fibra em detergente ácido & 33,78 & 45,43 & 5,81 & 10,00 & 13,46 \\
\hline Energia metabolizável (MJ/kg MS) & $9,5^{a}$ & $7,8 \mathrm{~b}$ & 13,32 & $12,0^{\mathrm{c}}$ & 11,3 \\
\hline
\end{tabular}

a NRC (1996); ${ }^{\mathrm{b}}$ Kearl (1982); c Terrill et al. (1998).

Tabela 2 - Composição das rações concentradas

\begin{tabular}{|c|c|c|c|c|c|}
\hline \multirow[t]{2}{*}{ Ingrediente } & \multicolumn{5}{|c|}{ Nível de milheto nas rações concentradas (\%MS) } \\
\hline & 0 & 23 & 49 & 80 & 96 \\
\hline & \multicolumn{5}{|c|}{ Composição percentual (\%MN) } \\
\hline Milheto moído & - & 23,0 & 48,8 & 80,0 & 96 \\
\hline Farelo de algodão & 31 & 28,0 & 24,9 & 18,5 & - \\
\hline Sal mineral & 1,5 & 1,5 & 1,5 & 1,5 & 1,5 \\
\hline Matéria seca (\%) & 91,22 & 91,38 & 91,74 & 92,05 & 92,16 \\
\hline Matéria orgânica & 95,11 & 95,10 & 95,07 & 95,08 & 95,86 \\
\hline Proteína bruta & 21,91 & 21,90 & 22,00 & 21,09 & 21,08 \\
\hline Matéria mineral & 4,89 & 4,90 & 4,93 & 4,92 & 4,14 \\
\hline Extrato etéreo & 5,19 & 5,13 & 5,07 & 5,02 & 5,31 \\
\hline Carboidratos totais & 68,00 & 68,07 & 68,00 & 68,97 & 69,47 \\
\hline
\end{tabular}

Tabela 3 - Composição química das dietas experimentais (\%MS)

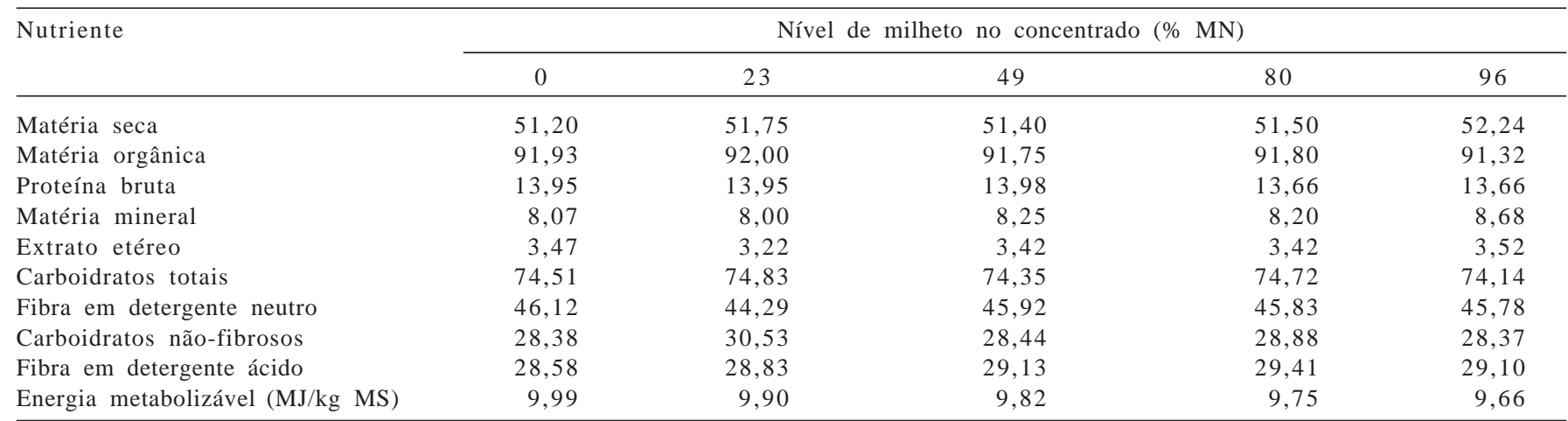

\section{Resultados e Discussão}

A análise de variância não mostrou efeito $(\mathrm{P}>0,05)$ da substituição do milho e farelo de algodão pelo milheto do concentrado no consumo de MS dos animais do ensaio de digestibilidade, em quaisquer das unidades de expressão, todavia a análise de regressão acusou significância quando o consumo de MS foi expresso em 
Tabela 4 - Consumo de matéria seca e coeficiente de digestibilidade aparente dos nutrientes de dietas com diferentes níveis de milheto

\begin{tabular}{|c|c|c|c|c|c|c|c|c|}
\hline \multirow[t]{2}{*}{ Parâmetros } & \multicolumn{5}{|c|}{ Nível de milheto (\%MN) } & \multirow{2}{*}{\multicolumn{2}{|c|}{ Regressão }} & \multirow[t]{2}{*}{$\mathrm{R}^{2}$} \\
\hline & 0 & 23 & 49 & 80 & 96 & & & \\
\hline \multicolumn{9}{|c|}{ Consumo } \\
\hline $\mathrm{kg} / \mathrm{dia}$ & 5,64 & 5,31 & 5,17 & 5,09 & 4,68 & 14,10 & $y=5,18$ & \\
\hline$\% \mathrm{PV}$ & 2,91 & 2,85 & 2,64 & 2,66 & 2,50 & 9,85 & $y=2,9114-0,0039 x$ & $\left(\mathrm{R}^{2}=88,83\right)$ \\
\hline $\mathrm{g} / \mathrm{kgPV}^{0,75}$ & 108,47 & 105,42 & 98,72 & 98,99 & 92,53 & 10,64 & $\mathrm{y}=108,3032-0,1507 \mathrm{x}$ & $\left(\mathrm{R}^{2}=90,78\right)$ \\
\hline \multicolumn{9}{|c|}{ Digestibilidade (\%) } \\
\hline Matéria seca & 60,46 & 58,63 & 61,38 & 59,34 & 61,79 & 3,58 & $\mathrm{y}=60,32$ & \\
\hline Proteína bruta & 63,99 & 58,34 & 62,59 & 57,82 & 65,36 & 6,66 & $y=61,63$ & \\
\hline Extrato etéreo & 89,31 & 85,95 & 81,15 & 76,73 & 80,67 & 6,32 & $y=88,2399-0,1108 x$ & $\left(\mathrm{R}^{2}=78,55\right)$ \\
\hline Carboidratos totais & 61,32 & 60,15 & 63,08 & 61,81 & 63,19 & 3,70 & $\mathrm{y}=61,91$ & \\
\hline Fibra em detergente neutro & 41,50 & 43,07 & 46,84 & 45,82 & 47,54 & 7,49 & $\mathrm{y}=42,0471+0,0590 x$ & $\left(\mathrm{R}^{2}=81,95\right)$ \\
\hline Fibra em detergente ácido & 37,42 & 36,27 & 40,59 & 41,30 & 42,69 & 9,40 & $y=36,5498+0,0626 x$ & $\left(\mathrm{R}^{2}=83,85\right)$ \\
\hline Nutrientes digestíveis totais & 61,35 & 59,64 & 61,54 & 60,15 & 62,92 & 3,59 & $\mathrm{y}=61,62$ & \\
\hline
\end{tabular}

$\% \mathrm{PV}$ e g/kgPV 0,75 (Tabela 4). O consumo diminuiu 0,004\% do PV e $0,151 \mathrm{~g} / \mathrm{kgPV}^{0,75}$ para cada $1 \%$ de aumento de milheto. Considerando as dietas contendo milho ou milheto exclusivos, as diferenças no consumo foram de 17,02; 11,70 e $14,70 \%$ quando determinados em $\mathrm{kg} / \mathrm{dia}$, \% PV e g/kgPV ${ }^{0,75}$. Este resultado sugere que o milheto apresenta palatabilidade ligeiramente inferior à do milho quando fornecido a animais mais jovens. Damesma forma, Hill \& Hanna (1990), trabalhando com novilhas jovens em confinamento também observaram menor consumo de MS ao substituírem o milho e farelo de soja pelo milheto. Gelaye et al. (1997) observaram que a substituição do milho pelo milheto na dieta de cabritos jovens causou menor consumo de MS, entretanto o mesmo não ocorreu com cabras em lactação. Por outro lado, Gonçalves et al. (2010) substituíram o milho pelo milheto na dieta de novilhos nelores jovens em ensaio de digestibilidade, e não observaram diferença significativa no consumo de MS, entretanto, o valor deste parâmetro foi de 7\% menor na dieta com milheto. Resultado semelhante foi observado por Nascimento et al. (2009), os quais avaliando fontes de energia em suplementos múltiplos para animais em pastejo, também não detectaram diferenças no consumo de MS entre dietas que continham milho ou milheto; porém, o milheto proporcionou consumo 6\% maior. De modo geral o consumo de MS observado na presente trabalho foi compatível com a idade e condição corporal dos animais.

Os coeficientes de digestibilidade da matéria seca (MS), proteína bruta (PB) carboidratos totais, bem como os valores dos nutrientes digestíveis totais (NDT) das dietas não foram $(\mathrm{P}>0,05)$ influenciados pela substituição do milho e farelo de algodão por milheto. Trabalhando com animais em pastejo alimentados com diferentes fontes de energia, em suplementos múltiplos, Nascimento et al. (2009) observaram valores de digestibilidade da MS, MO e carboidratos totais semelhantes entre as dietas contendo milho ou milheto. Contudo, a digestibilidade da PB nos animais que receberam do suplemento contendo milheto foi maior. Os autores atribuíram o resultado à baixa degradação ruminal da proteína $\alpha$-zeina presente no milho.

A digestibilidade do EE diminuiu de forma linear $(\mathrm{P}<0,05)$ com o aumento de milheto nas dietas. As proporções dos ingredientes nas dietas, seus teores de EE e respectivas digestibilidades podem ter gerado algum efeito associativo e ter causado este comportamento para a digestibilidade do EE. Resultado semelhante foi observado por Hill et al. (1996) ao substituírem $67 \%$ do milho e o farelo de soja por milheto. De acordo com esses autores não havia razões aparente para a diminuição da digestibilidade do EE, porém sugeriram que a digestibilidade do EE do milheto utilizado naquele experimento era menor que a do milho. Por outro lado Hill \& Hanna(1990) observaram valores similares para digestibilidade do EE do milho e milheto, enquanto Gonçalves et al. (2010) verificaram aumento na digestibilidade do EE ao substituírem o milho pelo milheto. Nascimento et al. (2009) detectaram valores de digestibilidade do EE variados, em vista do elevado coeficiente de variação e a valores negativos de digestão que originaram médias de digestibilidade muito baixas. Esse resultado, segundo os autores, foi proporcionado pelo baixo teor de EE das dietas; menores que 2,8 \%MS.

As digestibilidades da FDN e FDA aumentaram com o aumento da inclusão de milheto na dieta. Considerando a semelhança nos teores de fibra dos alimentos e das dietas, pode-se especular sobre sua composição da fibra.

Um fator que pode ter contribuído para maior digestibilidade da fibra foi uma possível maior degradabilidade da proteína do milheto e conseqüente maior oferta de amônia para os microrganismos celulolíticos. Com base em ensaio de metabolismo Hill \& Hanna (1990) sugeriram que em 
dietas com milheto a proteína foi mais degradada que em outras com milho e sorgo. Entretanto, Hill \& Hanna (1990) detectaram menor digestibilidade da FDN e FDA em dietas com milheto, e presumiram que a causa foi a maior taxa de fermentação do amido, traduzida pelo menor pH ruminal e maior produção de ácidos graxos voláteis, em relação à dieta com milho. Salienta-se que as dietas utilizadas por Hill \& Hanna (1990) continham apenas 20\% de volumoso. Hill et al. (1996) trabalhando com dietas semelhantes e substituição parcial (50 ou 67\%) do milho e o farelo de soja pelo milheto não detectaram alterações na digestibilidade da fibra; do mesmo modo Gonçalves et al. (2010) não observaram diferenças na digestibilidade da FDN e FDA quando substituíram 50 e $100 \%$ do milho por milheto. Esses autores registraram valores de digestibilidade da FDN e FDA muito próximos e com média de 38,0 e 37,6\%, quando o volumoso era silagem de milho, e de 50,0 e 51,4\% quando o volumoso era silagem de capim-elefante feita com 13\% de polpa cítrica. Valores estes bastante próximos aos observados no presente trabalho.

Os valores de NDT não foram influenciados pelos níveis de milheto das dietas; este resultado sugere que o milheto apresenta valor energético similar ao do milho. Todavia, Hill \& Hanna (1990) e Hill et al. (1996) trabalhando com bovinos de corte e Terrill et al. (1998) trabalhando com cabritos observaram que o milheto contém menor teor de energia que milho, mas não observaram diferenças no ganho de peso. De acordo com Nascimento et al. (2009) dietas à base de mistura mineral, uréia, farelo de algodão e milho ou milheto, para animais em pastejo, proporcionaram valores de NDT $(59,5 \% \times 61,6 \%)$ e de GPV $(0,74 \times 0,61 \mathrm{~kg} / \mathrm{dia})$ semelhantes. Trabalhando com garrotes nelores Gonçalves et al. (2010) substituíram o milho pelo milheto e não detectaram diferenças na digestibilidade dos nutrientes, presumindo-se que os teores de NDT das dietas também tenham sido similares.

Considerando o maior teor de proteína bruta do milheto (Tabela 1), a menor digestibilidade do EE (Tabela 2) e que nem toda proteína é metabolizada para produção de energia, pode-se inferir que o milheto contém menos energia que o milho. Dietas com $80 \%$ de concentrados utilizadas por
Hill \& Hanna (1990) e Hill et al. (1996), onde o milheto substituía 50, 67 e 100\% do milho, os valores de NDT foram iguais ou maiores que $67,3 \%$ e, portanto, maiores que os observados neste trabalho, o que pode ser atribuído à menor proporção de concentrado (40\%).

O ganho de peso vivo diário (GPV), o consumo de matéria seca (CMS) e a conversão alimentar (CA) não foram $(\mathrm{P}>0,05)$ afetados pela presença do milheto nas dietas (Tabela 5). Este resultado confirma aquele observado no ensaio de digestibilidade sugerindo que o milheto tem valor energético equivalente ao do milho, e ainda, permite substituir o concentrado protéico na dieta de novilhos confinados, com potencial de ganho de peso vivo médio de 1,0 kg/dia. Resultados similares foram observados por Hill et al. (1996), que ao substituírem $67 \%$ do milho e $100 \%$ do farelo de soja por milheto, também não registraram diferenças no ganho diário de novilhos; os animais que receberam milho e farelo de soja ganharam $1,87 \mathrm{~kg} / \mathrm{dia}$ e aqueles alimentados com milheto 1,76 kg/dia. Em experimento concomitante, os mesmos autores observaram que a substituição de $50 \%$ do milho e $100 \%$ do farelo de soja por milheto, em dietas de alto concentrado para novilhas, também não afetou o ganho diário $(1,28 \times 1,33 \mathrm{~kg} / \mathrm{dia})$. Por outro lado, é possível que a substituição total do milho e da fonte protéica pelo milheto possa limitar o desempenho de animais mais jovens. Neste sentido, Hill \& Hanna (1990), detectaram menor ( $<<0,20)$ ganho diário $(1,16 \mathrm{~kg})$ em novilhas de corte jovens (238 kgPV) alimentadas com milheto, em relação aquelas que receberam milho e farelo de soja (1,37 kg/dia). Confirmando esta tendência Gelaye et al. (1997), trabalhando com cabras em crescimento, também registraram diminuição no ganho diário e na conversão alimentar quando substituíram 50 ou $100 \%$ do milho e farelo de soja pelo milheto; porém os autores não observaram efeitos na produção e composição do leite de cabras com produção de $2,5 \mathrm{~kg} / \mathrm{dia}$. Resultados semelhantes foram observados por França et al. (1997) quando substituíram o milho e farelo de algodão pelo milheto na dieta de cabras em lactação.

O menor desempenho de categorias de animais mais novos pode ser devido à menor densidade energética das dietas com milheto, conforme relataram Hill et al. (1996) e

Tabela 5 - Ganho de peso vivo, consumo de matéria seca e conversão alimentar de acordo com os níveis de milheto

\begin{tabular}{|c|c|c|c|c|c|c|c|c|}
\hline \multirow[t]{2}{*}{ Parâmetro } & \multicolumn{5}{|c|}{ Nível de milheto } & \multirow[t]{2}{*}{$\mathrm{CV}$} & \multirow[t]{2}{*}{ Regressão } & \multirow[t]{2}{*}{$\mathrm{R}^{2}$} \\
\hline & 0 & 23 & 49 & 80 & 96 & & & \\
\hline Ganho de peso vivo (kg/dia) & 0,968 & 1,041 & 0,941 & 1,075 & 1,066 & 10,8 & $\mathrm{y}=1,018$ & 37,7 \\
\hline Consumo de MS (kg/dia) & 8,33 & 8,91 & 8,40 & 9,04 & 8,86 & 5,6 & $\mathrm{y}=8,70$ & 36,8 \\
\hline$\% \mathrm{PV}$ & 1,82 & 1,90 & 1,81 & 1,89 & 1,87 & 7,8 & $y=1,86$ & 15,8 \\
\hline $\mathrm{g} / \mathrm{kgPV}^{0,75}$ & 85,12 & 90,04 & 85,63 & 91,21 & 89,48 & 5,6 & $\mathrm{y}=88,29$ & 34,8 \\
\hline Conversão alimentar (kgMS/kg) & 10,21 & 9,37 & 9,82 & 9,11 & 9,24 & 13,0 & $\mathrm{y}=9,55$ & 60,5 \\
\hline
\end{tabular}


Terrill et al. (1998). Quanto à proteína, Hill \& Hanna (1990) e Hill et al. (1996), em ensaio de metabolismo, verificaram balanço de nitrogênio favorável às dietas contendo milheto; por outro lado, Ribeiro et al. (2004) ponderaram que o farelo de soja é adequado em lisina e sua substituição pelo milheto pode diminuir o teor de proteína do leite, entretanto, a produção de leite e de gordura não foi influenciada pela substituição do milho e parcial do farelo de soja pelo milheto.

O consumo de matéria seca pelos animais confinados não foi afetado $(\mathrm{P}>0,05)$ pela adição de milheto às dietas. Portanto, pode-se sugerir que o milheto é tão palatável quanto à mistura milho mais farelo de soja para novilhos confinados, lembrando, porém, que no ensaio de digestibilidade animais mais jovens diminuíram o consumo com o aumento da inclusão de milheto na dieta. Por outro lado Hill et al. (1996), registraram consumo de MS de $0,4 \mathrm{~kg} /$ dia maior (10,7 × 11,1 kg/dia) quando $67 \%$ do milho e o farelo de soja foram substituídos pelo milheto na dieta de novilhos confinados. Em outro ensaio utilizando novilhas os autores observaram que dietas onde o milheto substituiu $50 \%$ do milho e $100 \%$ do farelo de soja, foram mais consumidas (10,2 kg/dia) em comparação aquelas com milho (8,8 kg/dia), porém, não houve reflexo no ganho de peso. Hill \& Hanna (1990), no entanto, registraram consumo de MS de 0,9 kg/dia maior, por novilhas jovens alimentadas com milho e farelo de soja em comparação ao milheto, o que refletiu em diferença de $0,210 \mathrm{~kg} /$ dia no ganho de peso. Ribeiro et al. (2004) trabalhando com vacas em lactação e Gonçalves et al. (2010) com novilhos nelores, não detectaram alterações no consumo de nutrientes ao substituírem o milho pelo milheto.

A substituição do milho e farelo de algodão pelo milheto não afetou $(\mathrm{P}>0,05)$ a conversão alimentar. Por outro lado, Hill \& Hanna (1990), com substituição total, e Hill et al. (1996), com substituição parcial (67\%) do milho e total do farelo de soja pelo milheto na dieta de novilhos ou de $50 \%$ na dieta de novilhas, observaram conversão alimentar ligeiramente desfavorável ao milheto.

\section{Conclusões}

A substituição parcial ou total do milho e farelo de algodão por milheto no concentrado para bovinos em confinamento com potencial de ganho médio diário de
1,1 kg/dia pode ser realizada, pois não prejudica a digestibilidade dos nutrientes nem o desempenho animal.

\section{Referências}

AGRICULTURAL AND FOOD RESEARCH COUNCIL-AFRC. Energy and protein requirements of ruminants. Wallingford: CAB International, 1993. 150p.

FRANÇA, A.F.S.; ORSINE, G.F.; DIAS, M.J. et al. Utilização do milheto como substituto do milho em rações para cabras leiteiras. Anais da Escola de Agronomia e Veterinária v.27, n.1, p.121-126, 1997.

GELAYE, K.; TERRILL, T.; AMOAH, E.A. et al. Nutritional value of pearl millet for lactating and growing goats. Journal of Animal Science, v.75, p.1409-1414, 1997.

GONÇALVES, J.R.S.; PIRES, A.V.; SUSIN, I. et al. Substituição do grão de milho pelo grão de milheto em dietas contendo silagem de milho ou silagem de capim-elefante na alimentação de bovinos de corte. Revista Brasileira de Zootecnia, v.39, n.9, p.2032-2039, 2010 .

HILL, G.M.; HANNA, W.W. Nutritive characteristics of pearl millet grain in beef cattle diets. Journal of Animal Science, v.68, p.2061-2066, 1990.

HILL, G.M.; NEWTON, G.L.; STREETER, M.N. et al. Digestibility and utilization of pearl millet diets fed to finishing beef cattle. Journal of Animal Science, v.74, n.7, p.1728- 1735, 1996.

KEARL, L.C. Nutrient requirements of ruminant developing Countries. Logan: Utah State University, 1982. 381p.

KUMAR, A. O milheto como cultura granífera para ração. In: WORKSHOP INTERNATIONAL DE MILHETO, 1999, Planaltina. Anais... Planaltina: EMBRAPA CERRADOS, 1999. p.113-131.

NASCIMENTO, M.L.; PAULINO, M.F.; DETMANN, E. et al. Fontes de energia em suplementos múltiplos para recria de novilhos mestiços em pastejo durante o período de transição seca/águas: desempenho produtivo e características nutricionais. Revista Brasileira de Zootecnia, v.38, n.6, p.1133-1141, 2009.

NATIONAL RESEARCH COUNCIL - NRC. Nutrient requirements of beef cattle. 7.ed. Washington, D.C.: National Academy of Science, 1996. 242p.

NATIONAL RESEARCH COUNCIL - NRC. Nutrient requirements of dairy cattle. 7.ed. Washington, D.C.: National Academy of Science, 2001. 381p.

RIBEIRO, C.V.M.; PIRES, A.V.; SIMAS, J.M.C. et al. Substituição do grão de milho pelo de milheto (Pennisetum americanum) na dieta de vacas em lactação. Revista Brasileira de Zootecnia, v.33, n.5, p.1351-1359, 2004.

SILVA, D.J. Análise de alimentos: métodos químicos e biológicos. Viçosa, MG: UFV, 1981. 166p.

SNIFFEN, C.J.; O’CONNOR, J.D.; VAN SOEST, P.J. et al. A net carbohydrate and protein system for evaluating cattles diets II. Carbohydrate and protein availability. Journal of Animal Science, v.70, p.3351-3361, 1992

STATISTICAL ANALYSIS SYSTEM - SAS. User's guide. Version 6, 4.ed. Cary: 1990. v.2, 846p.

TERRILL, T.H.; GELAYES, S.; AMOAH, E.A. et al. Protein and energy value of pearl millet grain for mature goats. Journal of Animal Science, v.76, n.10, p.1964-1969, 1998. 